\title{
Relationship between periodontal status and disease activity in patients with ankylosing spondylitis
}

\author{
Ayşe Ünal Enginar ${ }^{1}$ ID , Özlem Daltaban² ID ${ }^{\text {Cahit Kaçar }}{ }^{3}$ ID, Tiraje Tuncer $^{3}$ ID \\ ${ }^{1}$ Department of Rheumatology, Ordu State Hospital, Turkey \\ ${ }^{2}$ Department of Periodontology, Faculty of Dentistry, Akdeniz University, Antalya, Turkey \\ ${ }^{3}$ Department of Rheumatology, Department of Physical Medicine and Rehabilitation, Akdeniz University School of Medicine, \\ Antalya, Turkey
}

\begin{abstract}
Objectives: Ankylosing spondylitis (AS) is a chronic inflammatory disease mainly affecting the spine and sacroiliac joints, characterized by enthesitis. Recent studies have investigated the relationship between AS and periodontitis. The aim of this study was to evaluate the periodontal status of patients with AS and to determine the factors affecting this.

Material and methods: The study included 200 AS patients, of which 129 were taking anti-tumour necrosis factor (TNF) drugs and 71 were taking non-steroid anti-inflammatory drugs (NSAID). Patients did not change their medication during the study. Disease activity was evaluated with the Bath Ankylosing Spondylitis Disease Activity Index (BASDAI), mobility with the Bath Ankylosing Spondylitis Metrology Index (BASMI), functional status with the Bath Ankylosing Spondylitis Functional Index (BASFI), enthesitis with the integrated Maastricht Ankylosing Spondylitis Enthesitis Score (MASES), and quality of life with the Ankylosing Spondylitis Quality of Life (ASQoL) scale. Data related to erythrocyte sedimentation rate, and C-reactive protein were recorded from the hospital information system. The plaque index (PI), gingival index (GI), pocket depth (PD), attachment level (CAL) measurements, and bleeding index (BOP) were measured.

Results: The results showed that $35.5 \%$ of the AS patients had periodontitis, at a lower rate in the anti-TNF group than in the NSAID group, but the difference was not statistically significant. Periodontitis-related factors were found to be age, BASFI and BASMI. A significant relationship was found between MASES and BOP and GI.

Conclusions: This suggests that periodontitis may be an enthesis in AS. Nevertheless, further studies are needed to explain the mechanism of periodontitis in AS patients.
\end{abstract}

Key words: periodontitis, ankylosing spondylitis, enthesitis, anti-TNF drugs.

\section{Introduction}

Ankylosing spondylitis (AS) is a disease primarily affecting the spine and sacroiliac joints, which is characterised by inflammatory lower back pain, enthesitis and new bone formation. The prevalence of AS is approximately $0.1-1.4 \%$ and it is seen in males $2-3$ fold more frequently than in females.

The age of onset is younger than 30 years in $80 \%$ of cases and $<5 \%$ of cases have onset after the age of 45 years. Enthesitis is inflammation of the attachment site of the tendons, ligaments and the joint capsule to the bone, and it is a characteristic feature of seronegative spondyloarthropathies (SpA). Enthesitis can be determined clinically in $10 \%$ of patients with early stage AS, and in $50 \%$ of advanced stage AS patients [1].

Periodontal disease is the general term for chronic inflammatory diseases of the tissues around the tooth. The periodontal tissues include the gingiva, alveolar bone, cement and the periodontal ligament, which has a supportive function attaching the tooth to the bone. 
This function is provided by the basic fibres of the periodontal ligament, which form a strong connection between the cement and the bone. The most important part of the periodontal ligament is formed of the principal fibrils, which are attached at one end to the bone and at the other end to the dental cement with Sharpey fibres [2].

The prevalence of periodontitis shows variation from country to country, but it has been reported to affect 20$50 \%$ of the global population [3]. The aetiology of periodontitis is multifactorial, with known risk factors of smoking, age, diabetes mellitus, education level, gender and immunological diseases such as human immunodeficiency virus (HIV) [3-5]. Many studies have shown a strong relationship between rheumatoid arthritis and periodontitis [6].

The aim of this study was to evaluate the periodontal status of patients with AS and to determine the factors affecting this relationship.

\section{Material and methods}

The study included 200 patients diagnosed with AS according to the modified New York criteria [7] and followed up in the rheumatology policlinic. Patients were excluded from the study if they were pregnant, had diabetes, or were aged $<18$ years. The study protocol was approved by the Akdeniz University Ethics Committee (Project No. 3918).

A record was made for all the patients of age, gender, body mass index, comorbidities, smoking status, disease duration and drug treatments. The patients were separated into two groups: those taking non-steroid antiinflammatory drugs (NSAID) and those taking anti-tumour necrosis factor drugs (anti-TNF). Disease activity was evaluated with the Bath Ankylosing Spondylitis Disease

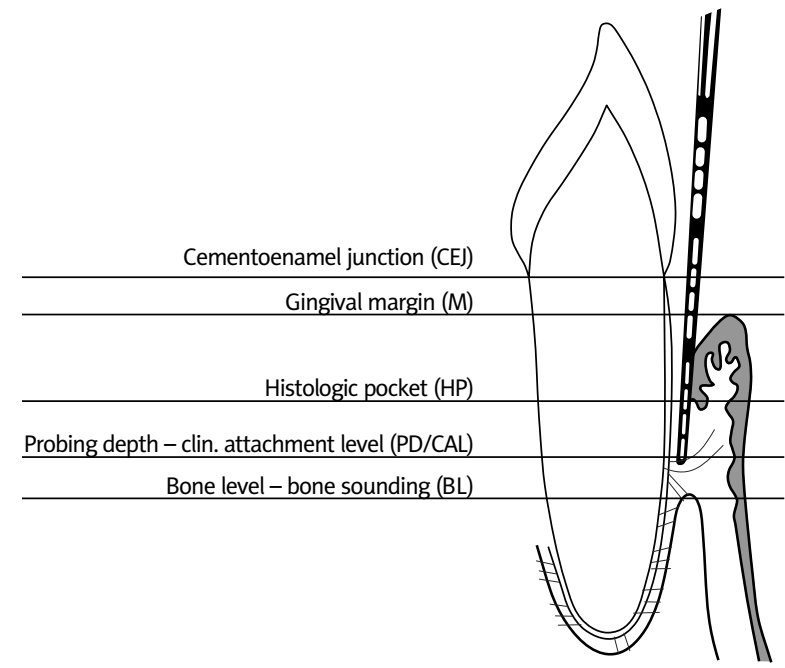

Fig. 1. Periodontal probing.
Activity Index (BASDAI), mobility with the Bath Ankylosing Spondylitis Metrology Index (BASMI), functional status with the Bath Ankylosing Spondylitis Functional Index (BASFI), enthesitis with the integrated Maastricht Ankylosing Spondylitis Enthesitis Score (MASES), and quality of life with the Ankylosing Spondylitis Quality of Life (ASQoL) scale. The erythrocyte sedimentation rate (ESR) and C-reactive protein (CRP) values were recorded from the hospital information system.

Periodontal examinations were conducted in the periodontology clinic. The periodontal condition was thoroughly assessed using the clinical and radiographic criteria stated and defined according to the American Academy of Periodontology guidelines [8].

Full-mouth clinical periodontal measurements were recorded at six sites per tooth (mesio-buccal, vestibular, disto-buccal, disto-lingual, lingual, mesio-lingual), and the plaque index (PI) [9], gingival index (GI) [10], bleeding on probing (BOP), which was recorded as present or absent, probing depth (PD) and clinical attachment level (CAL) were recorded.

A Williams periodontal probe (Williams, Hu-Friedy, Chicago, IL, USA) was used for the clinical periodontal measurements, which were all performed by the same examiner. Probing depth (PD) was defined as the distance from the free gingival margin to the bottom of the sulcus or periodontal pocket.

Gingival recession was defined as the distance from the cemento-enamel junction (CEJ) to the free gingival margin. Clinical attachment level was defined as the distance from the cemento-enamel junction to the bottom of the sulcus or periodontal pocket and was calculated as the total of the PD and gingival recession measurements [11] (Fig. 1).

\section{Statistical analysis}

Data obtained in the study were analysed statistically using SPSS v. 25.0 software. Descriptive statistics of quantitative data were stated as mean and standard deviation (SD) values and categorical data as number (n) and percentage (\%).

Conformity of the data to normal distribution was assessed with the Shapiro-Wilk test. As the data did not show normal distribution, non-parametric tests were used. Correlation analysis was applied to examine the relationships between variables. A value of $p<0.05$ was accepted as statistically significant.

\section{Results}

Evaluation was made of a total of 200 patients, as 71 (35.5\%) in the NSAID group and 129 (64.5\%) in the 
anti-TNF drug group. The mean age of patients in the NSAID group and anti-TNF drug group was $39.39 \pm 10.1$ and $40.12 \pm 10.1$ years, respectively $(p=0.710)$.

The non-steroid anti-inflammatory drugs group comprised 30 (42.3\%) females and 41 (57.7\%) males, and the anti-TNF drug group comprised 27 (20.9\%) females and 102 (79.1\%) males. There were 26 (36.6\%) patients who smoked in the NSAID group and 52 (40.3\%) in the antiTNF group, with no statistically significant difference determined. Human leukocyte antigen (HLA) B27 positivity was determined in $63.4 \%$ of the NSAID group and $76.9 \%$ of the anti-TNF group.

Periodontitis was determined in 26 (36.6\%) patients of the NSAID group and in 45 (34.9\%) of the anti-TNF group, and the difference was not determined to be statistically significant. The time since diagnosis and duration of symptoms were longer, and BASMI, BOP and GI values were determined to be statistically significantly higher in the anti-TNF group.

Morning stiffness, MASES, BASDAI, ASQoL and CRP values were determined to be statistically significantly higher in the NSAID group. No difference was deter- mined between the groups for the other parameters (Table I).

A statistically significant correlation was determined between periodontitis and age $(p=0.007)$, BASFI $(p=0.024)$, BASMI ( $p=0.001), \mathrm{PI}, \mathrm{PD}, \mathrm{CAL}, \mathrm{BOP}$, and GI $(p=0.000)$. The mean age was 42 years in patients with periodontitis and 38 years in those without periodontitis. In the patients with periodontitis, the BASFI score was mean 3.2, BASMI: 4.2, PI: 2, PD: 2.9, CAL: 3.1, BOP: 0.4 , and GI: 1.6 .

In the patients without periodontitis, the BASFI score was mean 2.3, BASMI: 3.6, PI: 1.5, PD: 1.8, CAL: 1.9, BOP: 0.2 , and $\mathrm{Gl}: 1.2$.

A correlation was determined between MASES and BASDAI, BASFI, ASQoL, BOP, and GI values. The bleeding on probing and $G$ I values were determined to be higher in the anti-TNF group (Table II).

\section{Discussion}

Various studies have determined periodontal disease at a higher prevalence in patients with AS than in the healthy population [12-19].

Table I. Disease and treatment profile in patients with ankylosing spondylitis

\begin{tabular}{|c|c|c|c|c|c|c|c|c|c|}
\hline \multirow[t]{2}{*}{ Parameters } & \multicolumn{4}{|c|}{ NSAID } & \multicolumn{4}{|c|}{ Anti-TNF } & \multirow[t]{2}{*}{$p$-value } \\
\hline & $n$ & Mean & $\begin{array}{c}\text { Std. } \\
\text { deviation }\end{array}$ & Median & $n$ & Mean & $\begin{array}{c}\text { Std. } \\
\text { deviation }\end{array}$ & Median & \\
\hline Age & 71 & 39.39 & 10.187 & 40.00 & 129 & 40.12 & 10.185 & 40.00 & 0.710 \\
\hline Diagnosis duration & 71 & 8.1169 & 8.10434 & 5.0000 & 129 & 11.0039 & 7.04935 & 10.0000 & 0.000 \\
\hline Disease duration & 71 & 11.3563 & 8.75073 & 10.0000 & 129 & 15.3566 & 8.31302 & 15.0000 & 0.000 \\
\hline Morning stiffness & 71 & 28.68 & 35.161 & 15.00 & 129 & 12.83 & 23.921 & 0.00 & 0.000 \\
\hline BMI & 71 & 26.2037 & 4.27891 & 26.1719 & 129 & 26.6839 & 4.50607 & 25.9455 & 0.611 \\
\hline MASES & 71 & 1.8169 & 2.46872 & 0.0000 & 129 & 1.0853 & 2.46548 & 0.0000 & 0.008 \\
\hline BASDAI & 71 & 4.1169 & 2.20952 & 4.0000 & 129 & 3.0922 & 2.10623 & 2.7000 & 0.001 \\
\hline BASFI & 71 & 2.8127 & 2.29701 & 2.6000 & 129 & 2.5240 & 2.26384 & 2.0000 & 0.345 \\
\hline BASMI & 71 & 3.4930 & 1.29696 & 3.0000 & 129 & 4.0543 & 1.67383 & 4.0000 & 0.017 \\
\hline ASQOL & 71 & 7.0282 & 5.33177 & 6.0000 & 129 & 5.4806 & 4.96724 & 4.0000 & 0.046 \\
\hline ESR & 71 & 14.7042 & 12.707022 & 10.0000 & 129 & 12.3178 & 11.113044 & 9.00000 & 0.181 \\
\hline CRP & 71 & 0.76832 & 0.828167 & 0.60000 & 129 & 0.60938 & 0.939762 & 0.30000 & 0.016 \\
\hline $\mathrm{PI}$ & 71 & 1.7076 & 0.31339 & 1.6700 & 129 & 1.7320 & 0.32085 & 1.7100 & 0.649 \\
\hline PD & 71 & 2.2683 & 0.69454 & 2.2000 & 129 & 2.2697 & 0.70268 & 2.1900 & 0.918 \\
\hline $\mathrm{CAL}$ & 71 & 2.3530 & 0.76128 & 2.2600 & 129 & 2.3367 & 0.77973 & 2.2000 & 0.708 \\
\hline BOP & 71 & 0.2520 & 0.15648 & 0.1900 & 129 & 0.3443 & 0.19064 & 0.2900 & 0.000 \\
\hline Gl & 71 & 1.3151 & 0.27516 & 1.2500 & 129 & 1.4237 & 0.27727 & 1.4200 & 0.009 \\
\hline
\end{tabular}

ASQoL - Ankylosing Spondylitis Quality of Life, BASDAI - Bath Ankylosing Spondylitis Disease Activity Index, BASFI - Bath Ankylosing Spondylitis Functional Index, BASMI - Bath Ankylosing Spondylitis Metrology Index, BMI - body mass index, BOP - bleeding on probing, CAL - clinical attachment loss, CRP - C-reactive protein, ESR - erythrocyte sedimentation rate, GI - gingival index, MASES - Maastricht Ankylosing Spondylitis Enthesitis Score, NSAID - non-steroidal anti-inflammatory drug, PD - pocket probing depth, PI-plaque index, TNF - tumour necrosis factor. 
Table II. Disease activity scores, clinical, laboratory and periodontal parameters in ankylosing spondylitis

\begin{tabular}{|c|c|c|c|c|c|c|c|}
\hline \multirow[t]{2}{*}{ Parameters } & \multicolumn{3}{|c|}{ With periodontitis } & \multicolumn{3}{|c|}{ Without periodontitis } & \multirow[t]{2}{*}{$p$-value } \\
\hline & Mean & $\begin{array}{c}\text { Std. } \\
\text { deviation }\end{array}$ & Median & Mean & $\begin{array}{c}\text { Std. } \\
\text { deviation }\end{array}$ & Median & \\
\hline Age & 42.46 & 9.600 & 42.00 & 38.43 & 10.219 & 38.00 & 0.007 \\
\hline Diagnosis duration & 10.197 & 7.203 & 9.0000 & 9.858 & 7.757 & 9.0000 & 0.613 \\
\hline Disease duration & 14.338 & 8.200 & 13.0000 & 13.715 & 8.932 & 13.0000 & 0.551 \\
\hline Morning stiffness & 19.86 & 30.647 & 5.00 & 17.68 & 28.6 & 5.00 & 0.945 \\
\hline BMI & 26.59 & 3.686 & 26.0617 & 26.46 & 4.79 & 25.8264 & 0.499 \\
\hline MASES & 1.1549 & 2.20 & 0.0000 & 1.4496 & 2.630 & 0.0000 & 0.795 \\
\hline BASDAI & 3.5197 & 2.310 & 3.2000 & 3.4209 & 2.131 & 3.2000 & 0.851 \\
\hline BASFI & 3.2014 & 2.553 & 2.9000 & 2.3101 & 2.047 & 1.8000 & 0.024 \\
\hline BASMI & 4.2958 & 1.467 & 4.0000 & 3.6124 & 1.577 & 3.0000 & 0.001 \\
\hline ASQoL & 6.4648 & 5.033 & 5.0000 & 5.7907 & 5.201 & 4.0000 & 0.229 \\
\hline ESR & 13.633 & 11.398 & 10.00 & 12.90 & 11.94 & 9.00000 & 0.478 \\
\hline CRP & 0.87831 & 1.214 & 0.60000 & 0.54884 & 0.6492 & 0.30000 & 0.165 \\
\hline PI & 2.0459 & 0.2125 & 2.0300 & 1.5458 & 0.2066 & 1.5200 & 0.000 \\
\hline PD & 2.9490 & 0.64350 & 2.7700 & 1.8950 & 0.3656 & 1.8600 & 0.000 \\
\hline CAL & 3.1052 & 0.72385 & 2.8600 & 1.9226 & 0.3716 & 1.8900 & 0.000 \\
\hline BOP & 0.4977 & 0.15557 & 0.4600 & 0.2091 & 0.09867 & 0.2000 & 0.000 \\
\hline $\mathrm{Gl}$ & 1.6487 & 0.18658 & 1.6500 & 1.2401 & 0.20910 & 1.2300 & 0.000 \\
\hline
\end{tabular}

ASQoL - Ankylosing Spondylitis Quality of Life, BASDAI - Bath Ankylosing Spondylitis Disease Activity Index, BASFI - Bath Ankylosing Spondylitis Functional Index, BASMI - Bath Ankylosing Spondylitis Metrology Index, BMI - body mass index, BOP - bleeding on probing, CAL - clinical attachment loss, CRP - C-reactive protein, ESR - erythrocyte sedimentation rate, Gl - gingival index, MASES - Maastricht Ankylosing Spondylitis Enthesitis Score, PD - pocket probing depth, PI - plaque index.

Keller et al. [18] reported periodontal disease in $45 \%$ of AS patients and in $25.9 \%$ of a corresponding control group. Higher bacterial prevalence in AS patients has been associated with inadequate oral hygiene. In animal studies, a relationship has been found between HLA-B27 and alveolar bone loss [20].

Agrawal et al. [15] hypothesised that HLA-B27 could have a role in the interaction between AS and aggressive periodontitis. However, this hypothesis was based on a single case report of an AS patient with HLA-B27 positive aggressive periodontitis. That study also showed no relationship between HLA-B27 and periodontal findings such as CAL, PD and BOP [15].

In the current study, no significant difference was determined between HLA-B27 positive and negative patients with respect to periodontitis. In another study conducted on Caucasians, the sensitivity of HLA-A9 and $\mathrm{B} 15$ to aggressive periodontitis was determined to be increased [21].

Serum IL-2, IL- 6 and TNF- $\alpha$ levels are high in AS patients [22]. It has been determined that in periodontitis, pro-inflammatory cytokines such as IL-1, IL-2, IL-6, IL-17 and TNF- $\alpha$ in the gingival pocket fluid are increased, and cytokine levels decrease after periodontal treatment [23-27].
In a study by Fabri et al. [16], although there was an evident improvement in the periodontal parameters of AS patients following anti-TNF treatment, this improvement was not observed in RA patients. It is not clear whether periodontitis is a result of AS disease or whether it is more effective in the pathogenesis, as in RA.

Similarly, Erciyes et al. [28] determined that the periodontal health of AS patients was worse than that of a control group. It was reported that as similar pro-inflammatory cytokines have a role in both diseases, the course of both could be affected.

Ratz et al. [12] conducted a meta-analysis of 6 studies which compared periodontal measurements of AS patients and control cases. A positive correlation was seen between AS and the severity of periodontitis in all the studies, but it was only statistically significant in two studies.

Although there was no significant difference with respect to CAL and PD, the BOP values were significantly higher in the AS patients ( $p=0.0005)$ [11]. In the current study, the BOP and GI values were higher in the anti-TNF group than in the NSAID group.

In a previous study in which plaque samples were taken from axial SpA patients, although periodontitis prevalence was higher, no difference was seen compared to 
the control group with respect to microbial variety [29]. While the contribution of periodontitis to the pathogenesis of RA is clear, this has not yet been clarified for AS.

In a study by Kang et al. [13], a significant relationship was determined between periodontitis and reduced mobility in AS patients. In the current study, a significant relationship was determined between BASFI and BASMI values and periodontitis.

In a large cohort study of 6428 patients diagnosed with psoriatic arthritis (PSA) in Denmark, the incidence rates of periodontitis in the PsA patients were found to be significantly higher than in the reference population. When psoriatic arthritis patients were compared with patients with psoriasis only, the rate of periodontitis was determined to be higher [30].

Enthesis is a basic finding of AS and there is therefore a need for further studies to investigate whether periodontitis can be considered as an enthesis. More frequent periodontitis in PSA than psoriasis may support enthesitis.

In the current study, the MASES scores of both the NSAID and anti-TNF groups were low, but were determined to be lower in the anti-TNF group. The drugs used by both groups are known to be extremely effective in the treatment of enthesis.

Previous studies have shown that NSAIDs and antiTNF drugs provide improvement in periodontitis [31-33]. Therefore, as the current study patients were all using NSAIDs or anti-TNF drugs, the periodontitis and measurements could have been masked.

In a study by lordache et al. [34], there was shown to be a significant improvement in disease activity, inflammatory parameters and periodontal status with 24 hours after starting anti-TNF drugs without applying periodontal treatment in AS patients.

Ancuta et al. [35] also showed a significant improvement in disease activity and periodontal status in PSA patients at 6 months after starting anti-TNF drugs.

Białowąs et al. [36] reported that despite reduced disease activity with periodontal treatment in RA, there was no improvement in clinical and biochemical parameters in SpA patients. This shows that while the contribution to disease pathogenesis in RA is more evident, there may be a relationship with enthesis in AS.

In spondyloarthropathies group diseases, the periodontal area may be an enthesis region and therefore periodontitis may be an enthesis. Anti-TNF treatments are known to be effective for enthesis and thus the benefit of anti-TNF drugs, even without periodontal treatment, can be evaluated as part of the treatment of systemic inflammation.

\section{Conclusions}

In conclusion, when the results of the current study are examined, although a relationship was seen be- tween AS and periodontitis, there were the limitations of the cross-sectional design of the study and the lack of a control group. In spondyloarthropathies, periodontitis may be a component of the disease, in other words an enthesis.

No opinion that periodontitis could be an enthesis could be found in the literature. There is a need for further studies on this subject. Patients must be evaluated with respect to periodontitis in SpA group diseases.

\section{Acknowledgments}

This study was supported by Akdeniz University scientific research project coordination unit (Project No. 3918).

The authors declare no conflict of interest.

\section{References}

1. Braun J, Sieper J. Ankylosing spondylitis. Lancet 2007; 369: 1379-1390, DOI: 10.1016/S0140-6736(07)60635-7.

2. Williams RC. Periodontal disease. N Engl J Med 1990; 322: 373-382, DOI: 10.1056/NEJM199002083220606.

3. Nazir MA. Prevalence of periodontal disease, its association with systemic diseases and prevention. Int J Health Sci (Qassim) 2017; 11: 72-80.

4. Hajishengallis G. Periodontitis: from microbial immune subversion to systemic inflammation. Nat Rev Immunol 2015; 15: 30-44, DOI: 10.1038/nri3785.

5. Schmidt J, Jentsch H, Stingu CS, Sack U. General immune status and oral microbiology in patients with different forms of periodontitis and healthy control subjects. PLoS One 2014; 9: e109187, DOI: 10.1371/journal.pone.0109187.

6. Fuggle NR, Smith TO, Kaul A, Sofat N. Hand to mouth: a systematic review and meta-analysis of the association between rheumatoid arthritis and periodontitis. Front Immunol 2016; 7: 80, DOI: 10.3389/fimmu.2016.00080.

7. van der Linden S, Valkenburg HA, Cats A. Evaluation of diagnostic criteria for ankylosing spondylitis. A proposal for modification of the New York criteria. Arthritis Rheum 1984; 27 : 361-368, DOI: 10.1002/art.1780270401.

8. Armitage GC. Development of a classification system for periodontal diseases and conditions. Ann Periodontol 1999; 4: 1-6, DOI: 10.1902/annals.1999.4.1.1.

9. Silness J, Löe H. Periodontal disease in pregnancy. II. Correlation between oral hygiene and periodontal condition. Acta Odontol Scand 1964; 22: 121-135, DOI: 10.3109/ 00016356408993968.

10. Löe H, Silness J. Periodontal disease in pregnancy. I. Prevalence and severity. Acta Odontol Scand 1963; 21: 533-551, DOI: 10.3109/00016356309011240.

11. Wolf HF, Rateitschak EM, Rateitschak KH, Hassell TM (eds.). Color atlas of dental medicine: periodontology, $3^{\text {rd }}$ ed. Thieme Medical Publishers, New York and Stuttgart 2005.

12. Ratz T, Dean LE, Atzeni F, et al. A possible link between ankylosing spondylitis and periodontitis: a systematic review and meta- 
analysis. Rheumatology (Oxford) 2015; 54: 500-510, DOI: $10.1093 /$ rheumatology/keu356.

13. Kang EH, Lee JT, Lee HJ, et al. Chronic periodontitis is associated with spinal dysmobility in patients with ankylosing spondylitis. J Periodontol 2015; 86: 1303-1313, DOI: 10.1902/ jop.2015.150202.

14. Pischon N, Pischon T, Gülmez E, et al. Periodontal disease in patients with ankylosing spondylitis. Ann Rheum Dis 2010; 69 34-38, DOI: 10.1136/ard.2008.097212.

15. Agrawal N, Agarwal K, Varshney A, et al. Is there a common pathogenesis in aggressive periodontitis \& ankylosing spondylitis in HLA-B27 patient? Med Hypotheses 2016; 90: 63-65, DOI: 10.1016/j.mehy.2016.03.005.

16. Fabri GM, Pereira RM, Savioli C, et al. Periodontitis response to anti-TNF therapy in ankylosing spondylitis. J Clin Rheumatol 2015; 21: 341-345, DOI: 10.1097/RHU.0000000000000300.

17. Sezer U, Erciyas K, Pehlivan Y, et al. Serum cytokine levels and periodontal parameters in ankylosing spondylitis. J Periodontal Res 2012; 47: 396-401, DOI: 10.1111/j.1600-0765.2011. 01448.x.

18. Keller JJ, Kang JH, Lin HC. Association between ankylosing spondylitis and chronic periodontitis: a population-based study. Arthritis Rheum 2013; 65: 167-173, DOI: 10.1002/art.37746.

19. Ziebolz D, Douglas D, Douglas D, et al. Periodontal condition is associated with disease duration and motoric disabilities in patients with ankylosing spondylitis: results of a cross-sectional study. Rheumatol Int 2018; 38: 855-863, DOI: 10.1007/ s00296-018-4012-6.

20. Tatakis DN, Guglielmoni P. HLA-B27 transgenic rats are susceptible to accelerated alveolar bone loss. J Periodontol 2000; 71: 1395-1400, DOI: 10.1902/jop.2000.71.9.1395.

21. Stein JM, Machulla HK, Smeets R, et al. Human leukocyte antigen polymorphism in chronic and aggressive periodontitis among Caucasians: a meta-analysis J Clin Periodontol 2008; 35: 183-192, DOI: 10.1111/j.1600-051X.2007.01189.x.

22. Bal A, Unlu E, Bahar G, et al. Comparison of serum IL-1 beta, sIL-2R, IL-6, and TNF-alpha levels with disease activity parameters in ankylosing spondylitis. Clin Rheumatol 2007; 26: 211215, DOI: 10.1007/s10067-006-0283-5.

23. Holmlund A, Hänström L, Lerner UH. Bone resorbing activity and cytokine levels in gingival crevicular fluid before and after treatment of periodontal disease. J Clin Periodontol 2004; 31: 475-482, DOI: 10.1111/j.1600-051X.2004.00504.x.

24. Thunell DH, Tymkiw KD, Johnson GK, et al. A multiplex immunoassay demonstrates reductions in gingival crevicular fluid cytokines following initial periodontal therapy. J Periodontal Res 2009; 45: 148-152, DOI: 10.1111/j.1600-0765.2009.01204.x.
25. de Oliveira RR, Schwartz-Filho HO, Novaes AB, et al. Antimicrobial photodynamic therapy in the non-surgical treatment of aggressive periodontitis: cytokine profile in gingival crevicular fluid, preliminary results. J Periodontol 2009; 80: 98-105, DOI: 10.1902/jop.2009.070465.

26. Zhao L, Zhou Y, Xu Y, et al. Effect of non-surgical periodontal therapy on the levels of Th17/Th1/Th2 cytokines and their transcription factors in Chinese chronic periodontitis patients. J Clin Periodontol 2011; 38: 509-516, DOI: 10.1111/j.1600-051X. 2011.01712.x.

27. Ertugrul AS, Sahin H, Dikilitas A, et al. Comparison of CCL28, interleukin-8, interleukin-1beta and tumor necrosis factoralpha in subjects with gingivitis, chronic periodontitis and generalized aggressive periodontitis. J Periodontal Res 2013; 48: 44-51, DOI: 10.1111/j.1600-0765.2012.01500.x.

28. Erciyes K, Üstün K, Pehlivan Y, Onat AM. Ankylosing spondylitis and periodontal health. A pilot study. Atatürk Üniv Diş Hek Fak Derg 2009; 19: 151-155.

29. Bisanz JE, Suppiah P, Thomson WM, et al. The oral microbiome of patients with axial spondyloarthritis compared to healthy individuals. PeerJ 2016; 4: e2095, DOI: 10.7717/peerj.2095.

30. Egeberg A, Mallbris L, Gislason G, et al. Risk of periodontitis in patients with psoriasis and psoriatic arthritis. J Eur Acad Dermatol Venereol 2017; 31: 288-293, DOI: 10.1111/jdv.13814.

31. Jeffcoat $M$, Reddy $M$, Haigh $S$, et al. A comparison of topical ketorolac, systemic flurbiprofen, and placebo for the inhibition of bone loss in adult periodontitis. J Periodontol 1995; 66: 329-338, DOI: 10.1902/jop.1995.66.5.329.

32. Goncalves DC, Evangelista RC, da Silva RR, et al. Infliximab attenuates inflammatory osteolysis in a model of periodontitis in Wistar rats. Exp Biol Med (Maywood) 2014; 239: 442453, DOI: $10.1177 / 1535370213520114$.

33. Di Paola R, Mazzon E, Muià C, et al. Effects of etanercept, a tumour necrosis factor-alpha antagonist, in an experimental model of periodontitis in rats. Br J Pharmacol 2007; 150: 286-297, DOI: 10.1038/sj.bjp.0706979.

34. Iordache C, Chirieac R, Ancuta E, et al. Periodontal disease in patients with ankylosing spondylitis: myth or reality? Rev Chim 2017; 68: 1660-1664, DOI: 10.37358/RC.17.7.5740.

35. Ancuta C, Ancuta E, Chirieac R, et al. TNF inhibitors and periodontal inflammation in psoriatic arthritis. Rev Chim 2017; 68: 1914-1918, DOI: 10.37358/RC.17.8.5790.

36. Białowąs K, Radwan-Oczko M, Dus-Ilnicka I, et al. Periodontal disease and influence of periodontal treatment on disease activity in patients with rheumatoid arthritis and spondyloarthritis. Rheumatol Int 2020; 40: 455-463, DOI: 10.1007/ s00296-019-04460-z. 